Doi: $10.32481 / \mathrm{djph} .2021 .12 .015$

\title{
Disparities in Delaware Caregiver Beliefs about the COVID-19 Vaccine for their Children
}

Thao-Ly Tam Phan, MD, MPH; ${ }^{1}$ Paul T. Enlow, PhD; ${ }^{2}$ Michael K. Wong; ${ }^{3}$ Amanda M. Lewis, $\mathrm{MPH} ;{ }^{4}$ Anne E. Kazak, PhD, ABPP; ${ }^{5}$ Jonathan M. Miller, $\mathrm{MD}^{6}$

1. Associate Professor of Pediatrics, Thomas Jefferson University; Research Scientist, Nemours

Center for Healthcare Delivery Science

2. Assistant Professor of Pediatrics, Thomas Jefferson University; Assistant Research Scientist, Nemours Center for Healthcare Delivery Science

3. Medical Student, Thomas Jefferson University

4. Data Analyst, Nemours Center for Healthcare Delivery Science

5. Professor of Pediatrics, Thomas Jefferson University; Director, Nemours Center for Healthcare Delivery Science

6. Medical Director, Nemours Value-Based Services Organization; Chief of Primary Care Pediatrics, Nemours Children's Health - Delaware Valley

\begin{abstract}
Objective: To describe sociodemographic disparities in caregiver beliefs about the COVID-19 vaccine for their children. Methods: This was a cross-sectional study, linking caregiver-reported data to geocoded sociodemographic data from child EHRs. Caregivers of children receiving care in a Delaware pediatric healthcare system were invited to complete a survey about COVID-19 vaccine beliefs from March 19 to April 16, 2021. Results: 1499 caregivers participated (18\% Black, $11 \%$ Hispanic, $32 \%$ public insurance, $12 \%$ rural). $54 \%$ of caregivers intended to vaccinate their children, while $34 \%$ were unsure and $12 \%$ would not. Caregivers of younger children (aOR 3.70, CI 2.36-5.79), Black children (aOR 2.11, CI 1.50-2.96), and from disadvantaged communities (aOR 1.59, CI 1.05-2.42) were more likely to be unsure and not vaccinate their children. Caregivers from rural communities were more likely not to vaccinate their children (aOR 2.51, CI 1.56-4.05). Fewer caregivers of younger children, Black children, and from disadvantaged communities believed in the safety or efficacy of the vaccines $(p<0.001)$, while fewer caregivers of younger children and from rural communities believed in their children's susceptibility to COVID-19 or risk of getting severe disease from COVID-19 ( $<<0.05)$. While the majority $(72 \%)$ of caregivers were influenced by health experts, fewer from communities of color and disadvantaged communities were $(p<0.001)$. Conclusions: Caregivers of younger children and from communities of color, rural communities, and disadvantaged communities in Delaware expressed more COVID-19 vaccine hesitancy. Policy implications: This study explores beliefs of different communities in Delaware, which are important to tailoring public health messaging and strategies to increase vaccine uptake in these communities.
\end{abstract}

\section{Introduction}

The COVID-19 pandemic has exacerbated disparities in Delaware and across the United States, with communities of color, rural communities, and disadvantaged communities experiencing higher rates of COVID-19 transmission, morbidity and mortality ${ }^{1-3}$ and reduced rates of COVID- 
19 vaccination. ${ }^{4,5}$ The United States is still far from achieving herd immunity, with about 54\% of Delawareans being fully vaccinated and uptake for COVID-19 vaccines declining. ${ }^{6-8}$ Several studies in adults have demonstrated that Black adults, adults from rural areas, and adults from households with lower incomes have higher rates of COVID-19 vaccine hesitancy ${ }^{6,9-13}$ exacerbated by systemic issues of institutional racism, distrust of the healthcare system, misinformation, and complacency with the pandemic. ${ }^{14,15}$ However, there have been only a handful of studies assessing caregiver hesitancy towards a COVID-19 vaccine for their children, ${ }^{6,16-20}$ with the most recent national survey showing that less than half of caregivers in the United States were likely to vaccinate their children against COVID-19 and increased hesitancy among parents of younger children those with lower educational status and nonDemocratic affiliations. $^{20}$

With the COVID-19 vaccine increasingly becoming available for children, ${ }^{21,22}$ understanding factors that impact caregiver acceptance of COVID-19 vaccines for their children is critical to informing public health interventions and messaging. ${ }^{7}$ The Health Belief Model (HBM) is a validated conceptual framework used to describe factors, including beliefs about vaccine safety/efficacy, severity of/susceptibility to disease, and cues to action, that have impacted caregiver acceptance of the seasonal and H1N1 influenza vaccines for their children. ${ }^{23-25}$ Studies evaluating HBM constructs that impact adult acceptance of the COVID-19 vaccine for themselves ${ }^{26-30}$ have demonstrated the value in identifying what beliefs are commonly associated with vaccine hesitancy. Despite this there have been no studies formally evaluating the impact of HBM constructs on caregiver acceptance of the COVID-19 vaccine for their children. In addition, recent studies that have evaluated caregiver beliefs (e.g about vaccine safety) have not described differences in these beliefs between different demographic subgroups. ${ }^{20}$

Therefore, the objective of this study was to describe disparities in caregiver intention to vaccinate their children against COVID-19 in Delaware and differences among sociodemographic groups in caregiver beliefs that influence intention to vaccinate their children against COVID-19 through the lens of the HBM, leveraging linked EHR data and geocoded variables to define social determinants of health. Identification of hesitant populations and modifiable beliefs is critically important to developing tailored public health strategies in the state to promote equitable uptake of COVID-19 vaccines among children.

\section{Methods}

\section{Study Design and Participants}

A cross-sectional study was conducted, linking caregiver-reported survey data to child electronic health record (EHR) data. Families $(\mathrm{N}=2403)$ received an invitation to complete the survey for this study if they had consented to participating in a prospective cohort study about the impact of COVID-19 on families and pediatric healthcare delivery in October and November of 2020.

Families $(\mathrm{N}=15,000)$ were invited to participate in the prospective cohort study and were eligible if they had a scheduled outpatient visit in April 2020 to a large pediatric healthcare system in the Delaware Valley region of the United States. Families were excluded if the child was older than 21 years, if the caregiver was not proficient in English or Spanish, if a mobile phone number was not listed in the EHR, if the family had opted out of research participation, or if the child was not an established patient of the healthcare system (defined as having at least one other visit to the healthcare system in the prior 12 months). Families of children who were of Black race or 
Hispanic ethnicity, who had public insurance, or who were from rural neighborhoods [Rural Urban Commuting Area (RUCA) code $\geq 4]^{31}$ were oversampled, with all eligible families from these subgroups receiving an invitation to participate in the original study, and a random sample of eligible families from other subgroups receiving an invitation to participate. If a mobile number was available for more than one caregiver per family, both caregivers were invited to participate. This study was approved by the healthcare system's institutional review board (number 1613768), with caregivers of participating families signing an e-consent.

\section{Procedures}

A study identifier was created for all eligible participants in a REDCap database ${ }^{32}$ and information from each child's EHR was imported into the database. Text messages containing a hyperlink to the REDCap survey, unique to each eligible participant, were sent every three days to caregivers of all eligible families at the mobile number listed in the child's EHR from March 19, 2021 to April 16, 2021 until the survey was completed. An e-mail message describing the study and alerting the eligible participant to anticipate a text message with the survey link was sent at the beginning and at the end of the survey time period to increase survey response rates. ${ }^{33}$

\section{Caregiver Beliefs about the COVID-19 Vaccine for their Children}

Ten questions were included in a REDCap survey. In addition to a question about intention to vaccinate, an additional set of questions asked about five potential cues to action that might influence caregiver decisions to vaccinate their child against COVID-19, adapted for the pediatric population from a validated survey conducted among adults about the COVID-19 vaccine. ${ }^{29}$ A question representing each of the four primary HBM constructs (perceived susceptibility, severity, benefits, and barriers) was also included. Questions were adapted from a study of caregiver beliefs about the influenza vaccine for their child, with questions selected based on the strength of their association in the original study with child influenza vaccination. ${ }^{24}$

1) Do you plan to vaccinate your child(ren) against COVID-19 when they are eligible? (intention to vaccinate)

2) My decision to have my child(ren) vaccinated against COVID-19 is affected by (cues to action)
a. What I have seen/read on media (including social media)
b. What my friends and family say
c. What health experts think
d. What my or my child's doctor says
e. What my child's school says

3) My child(ren) would get sick more easily from COVID-19 than other child(ren) (perceived susceptibility)

4) COVID-19 could make my child(ren) very sick (perceived severity)

5) If my child(ren) get the vaccine, they won't get sick from COVID-19 (perceived benefit)

6) COVID-19 vaccines are unsafe for children (perceived barrier) 
Response options for question 1 included yes, no, and not sure. Response options for the remainder of the questions included strongly disagree, disagree, neither agree nor disagree, agree, and strongly agree. For the purpose of analyses, these responses were categorized as agree (including agree and strongly agree) or not.

\section{Child Sociodemographics}

Information on child race, ethnicity, age, insurance, and ZIP code were extracted from the child's EHR. For the purpose of analyses, child race and ethnicity were categorized as Non-Hispanic Black, Hispanic, Non-Hispanic White, or Non-Hispanic Other. Child age was categorized as 0-1 years, 2-11 years, 12-15 years, and 16 years or older to correspond to current and anticipated COVID-19 vaccine approval stages. Insurance status was categorized as private insurance, public insurance, or self-pay. ZIP code was used to categorize child neighborhoods as rural (RUCA code $\geq 4$ ) or not (RUCA code $<4$ ) and to categorize child neighborhood inequity based on overall Child Opportunity Index (COI, state-normed). The COI combines indicators of educational (e.g., early childhood education enrollment, high school graduation rate), health and environment (e.g., access to healthy food, health insurance coverage), and social and economic opportunity (e.g., employment rate, median household income) for all United States neighborhoods. ${ }^{34}$ These indicators are then used to categorize COI as very low, low, moderate, high, and very high.

\section{Analysis}

Descriptive analyses of child sociodemographics and caregiver responses to the survey items were performed. Pearson's Chi-Square tests were conducted to describe the association between caregiver intention to vaccinate and child sociodemographics. Multinomial logistic regression was conducted to further describe the association between intention to vaccinate as the primary outcome variable and child sociodemographics, including any variables in the analyses that were found to be significant with Pearson's Chi-Square testing and excluding any variables that were significantly associated with one another on tests of collinearity. Finally, Pearson's Chi-Square tests were conducted to describe the association between caregiver beliefs about the COVID-19 vaccine for their children and child sociodemographics. All tests were performed with SPSS v27 and at a significance level of $\mathrm{p}<0.05$.

\section{Results}

\section{Participant Sociodemographics}

1549 caregivers responded to the survey ( $60 \%$ of those who received the survey). The large majority were female (83\%) and with a preferred language of English (96\%). One hundred participants were caregivers for the same child and therefore 1449 children were represented in this survey (Table 1). The children in this sample were diverse and representative of the population, with $18 \%$ Black, $11 \%$ Hispanic, $32 \%$ having public insurance, and $12 \%$ from rural neighborhoods. There was a wide range of child ages and COI scores. $56 \%$ were patients seen in a primary care clinic of the pediatric healthcare system.

Table 1. Participant Characteristics

\begin{tabular}{|l|l|}
\hline Sociodemographic Variable & No. (\%) \\
\hline Total Families & $1449(100)$ \\
\hline
\end{tabular}


Doi: $10.32481 / \mathrm{djph} .2021 .12 .015$

\begin{tabular}{|l|l|}
\hline Child sex & \\
\hline Female & $721(50)$ \\
\hline Male & $728(50)$ \\
\hline Child age range & \\
\hline $0-1$ years & $163(11)$ \\
\hline $2-11$ years & $705(47)$ \\
\hline $12-15$ years & $341(23)$ \\
\hline 16 years and older & $290(19)$ \\
\hline Child race/ethnicity & \\
\hline Hispanic & $167(11)$ \\
\hline Black & $270(18)$ \\
\hline White & $869(58)$ \\
\hline Other & $193(13)$ \\
\hline Child insurance & \\
\hline Public & $484(32)$ \\
\hline Private & $972(65)$ \\
\hline Self-Pay & $43(3)$ \\
\hline Child Opportunity Index & \\
\hline Very low & $196(13)$ \\
\hline Low & $289(19)$ \\
\hline Moderate & $234(16)$ \\
\hline High & $265(18)$ \\
\hline Very high & $515(34)$ \\
\hline Neighborhood rurality & \\
\hline Non-Rural (RUCA $<4)$ & $1321(88)$ \\
\hline Rural (RUCA $\geq 4)$ & $178(12)$ \\
\hline & \\
\hline
\end{tabular}

\section{Caregiver Intention to Vaccinate Child against COVID-19 by Child Sociodemographics}

$54 \%$ of caregivers intended to vaccinate their children against COVID-19, while $34 \%$ were not sure and $12 \%$ would not (Table 2). Of the one hundred participants who were caregivers for the same child, $82 \%$ were in agreement about their intention to vaccinate their children against COVID-19 (e.g., both parents said they would vaccinate their child). There were significant differences by child sociodemographics, with fewer caregivers of children under 16 years, of Black race, with public insurance, from neighborhoods with lower COI, and from rural neighborhoods reporting they intended to vaccinate their children against COVID-19 ( $p<0.001$ for all variables, Table 2). In multinomial logistic regression analysis (Table 3), the pattern of associations was similar to the univariate analyses. Caregivers of younger children, Black children, children with public insurance, and children from neighborhoods with lower COI were more likely to both be unsure and report that they would not vaccinate their children against COVID-19. Caregivers from rural neighborhoods with lower COI were more likely to report that they would not vaccinate their children against COVID-19.

Table 2. Caregiver Intention to Vaccinate their Children Against COVID-19 by Sociodemographic Group 


\begin{tabular}{|l|l|l|l|l|}
\hline & $\begin{array}{l}\text { Yes } \\
\text { N (\%) }\end{array}$ & $\begin{array}{l}\text { No } \\
\text { N (\%) }\end{array}$ & $\begin{array}{l}\text { Not Sure } \\
\text { N (\%) }\end{array}$ & $\mathbf{P}$ \\
\hline Total & $\mathbf{8 0 8 ( 5 4 )}$ & $\mathbf{1 8 0 ( 1 2 )}$ & $\mathbf{5 1 1}(\mathbf{3 4 )}$ & \\
\hline Child age range & & & & $<0.001$ \\
\hline 0-1 years & $72(44)$ & $20(12)$ & $71(44)$ & \\
\hline 2-11 years & $358(51)$ & $95(14)$ & $252(36)$ & \\
\hline 12-15 years & $176(52)$ & $39(11)$ & $126(37)$ & \\
\hline 16 years and older & $202(70)$ & $26(9)$ & $62(21)$ & \\
\hline Child race/ethnicity & & & & $<0.001$ \\
\hline Hispanic & $94(56)$ & $17(10)$ & $56(34)$ & \\
\hline Non-Hispanic Black & $98(36)$ & $47(17)$ & $125(46)$ & \\
\hline Non-Hispanic White & $515(59)$ & $96(11)$ & $258(30)$ & \\
\hline Non-Hispanic Other & $101(52)$ & $20(10)$ & $72(37)$ & \\
\hline Child insurance & & & & $<0.001$ \\
\hline Public & $200(41)$ & $78(16)$ & $206(43)$ & \\
\hline Private & $585(60)$ & $97(10)$ & $290(30)$ & \\
\hline Self-Pay & $23(54)$ & $5(12)$ & $15(35)$ & \\
\hline Child Opportunity Index & & & & $<0.001$ \\
\hline Very low & $71(36)$ & $42(21)$ & $83(42)$ & \\
\hline Low & $148(51)$ & $44(15)$ & $97(34)$ & \\
\hline Moderate & $111(47)$ & $26(11)$ & $97(42)$ & \\
\hline High & $143(54)$ & $35(13)$ & $87(33)$ & \\
\hline Very high & $335(65)$ & $33(6)$ & $147(29)$ & \\
\hline Neighborhood rurality & & & & $<0.001$ \\
\hline Non-Rural (RUCA $<4)$ & $736(56)$ & $139(11)$ & $446(34)$ & \\
\hline Rural (RUCA $\geq 4)$ & $72(40)$ & $41(23)$ & $65(37)$ & \\
\hline
\end{tabular}

Table 3. Multinomial Logistic Regression Predicting Caregiver Intention to Vaccinate their Children Against COVID-19

\begin{tabular}{|l|l|l|}
\hline \multirow{2}{*}{ Child age range } & No vs. Yes & Not Sure vs. Yes \\
\cline { 2 - 3 } & $\mathrm{aOR}(95 \% \mathrm{CI})$ & $\mathrm{aOR}(95 \% \mathrm{CI})$ \\
\hline $0-1$ years & & \\
\hline $2-11$ years & $2.51(1.56-4.05)$ & $3.70(2.36-5.79)$ \\
\hline $12-15$ years & $2.10(1.30-3.40)$ & $2.31(1.65-3.30)$ \\
\hline 16 years and older & $1.78(1.02-3.09)$ & $2.41(1.65-3.51)$ \\
\hline Child race/ethnicity & $1[$ Reference $]$ & $1[$ Reference $]$ \\
\hline Hispanic & & \\
\hline Non-Hispanic Black & $0.68(0.37-1.23)$ & $0.88(0.59-1.30)$ \\
\hline
\end{tabular}


Doi: $10.32481 /$ djph.2021.12.015

\begin{tabular}{|l|l|l|}
\hline Other & $0.99(0.57-1.71)$ & $1.36(0.96-1.93)$ \\
\hline Non-Hispanic White & $1[$ Reference $]$ & 1 [Reference $]$ \\
\hline Child insurance & & \\
\hline Public & $1.82(1.26-2.65)$ & $1.82(1.39-2.37)$ \\
\hline Self-Pay & $1.29(0.47-3.56)$ & $1.27(0.64-2.52)$ \\
\hline Private & $1[$ Reference $]$ & $1[$ Reference $]$ \\
\hline Child Opportunity Index & & \\
\hline Very Low & $3.65(2.04-6.53)$ & $1.59(1.05-2.42)$ \\
\hline Low & $1.82(1.05-3.16)$ & $1.11(0.77-1.60)$ \\
\hline Moderate & $1.83(1.03-3.25)$ & $1.66(1.17-2.37)$ \\
\hline High & $2.13(1.26-3.62)$ & $1.25(0.89-1.76)$ \\
\hline Very High & $1[$ Reference $]$ & $1[$ Reference $]$ \\
\hline Neighborhood rurality & & \\
\hline Rural $($ RUCA $<4)$ & $2.51(1.56-4.05)$ & $1.42(0.96-2.11)$ \\
\hline Non-rural $($ RUCA $\geq 4)$ & $1[$ Reference $]$ & $1[$ Reference] \\
\hline
\end{tabular}

\section{Caregiver Health Behavior Beliefs about COVID-19 Vaccination for their Child by Sociodemographics}

The majority of caregivers agreed that COVID-19 could make their child very sick $(53 \%)$ and that healthcare experts (72\%) and their child's doctor (70\%) affect their decision to vaccinate their children (Table 4). Only 431 (29\%) of participants agreed that the media and only 340 $(23 \%)$ of participants agreed that friends and family affected their decision to vaccinate their children, with no differences among subgroups so these are not reported in Table 4 . However, there were significant differences between sociodemographic subgroups in other beliefs (Table 4). Fewer caregivers of younger children believed that their children are susceptible to COVID19, that COVID could be severe in their children, and that the COVID-19 vaccines are safe. Fewer caregivers of Black children believed that the COVID-19 vaccines are effective, and fewer caregivers of Black and Hispanic children believed that COVID-19 vaccines are safe and were influenced by health experts or doctors. Fewer caregivers of children with public insurance believed that their child was susceptible to COVID-19, that the COVID-19 vaccines are safe or effective, or were influenced by health experts, doctors, or schools. Similarly, fewer caregivers of children from neighborhoods with lower COI scores believed that the COVID-19 vaccines are safe or effective or were influenced by health experts or doctors. Finally, fewer caregivers from rural neighborhoods believed that COVID-19 could be severe in their children or were influenced by their child's school.

Table 4. Caregiver Agreement with Health Belief Model Items by Child Sociodemographic Group 


\begin{tabular}{|c|c|c|c|c|c|c|c|}
\hline & $\begin{array}{l}\text { Susceptible } \\
\text { to COVID } \\
\text { N (\%) }\end{array}$ & $\begin{array}{l}\text { Severity of } \\
\text { COVID } \\
\text { N (\%) }\end{array}$ & $\begin{array}{l}\text { Vaccine } \\
\text { effective } \\
\mathbf{N}(\%)\end{array}$ & $\begin{array}{l}\text { Vaccine } \\
\text { unsafe } \\
\mathbf{N}(\%)\end{array}$ & $\begin{array}{l}\text { Cue - } \\
\text { health } \\
\text { experts } \\
\text { N (\%) }\end{array}$ & $\begin{array}{l}\text { Cue- } \\
\text { child's } \\
\text { doctor } \\
\text { N }(\%)\end{array}$ & $\begin{array}{l}\text { Cue - } \\
\text { school } \\
\text { N (\%) }\end{array}$ \\
\hline Total & $462(31)$ & $792(53)$ & $375(25)$ & $154(10)$ & $1073(72)$ & $\begin{array}{l}1055 \\
(70)\end{array}$ & $\begin{array}{l}416 \\
(28)\end{array}$ \\
\hline \multicolumn{8}{|c|}{ Child age range } \\
\hline $0-1$ years & $20(13)$ & $73(47)$ & $41(26)$ & $17(11)$ & $114(72)$ & $112(70)$ & $55(35)$ \\
\hline $2-11$ years & $210(31)$ & $376(55)$ & $165(24)$ & $89(13)$ & $496(72)$ & $488(70)$ & $\begin{array}{l}199 \\
(29)\end{array}$ \\
\hline $12-15$ years & $106(32)$ & $170(52)$ & $88(27)$ & $29(9)$ & $246(73)$ & $243(73)$ & $\begin{array}{l}101 \\
(30)\end{array}$ \\
\hline $\begin{array}{l}16 \text { and } \\
\text { older }\end{array}$ & $127(45)$ & $173(62)$ & $81(29)$ & $19(7)$ & $217(75)$ & $212(74)$ & $61(21)$ \\
\hline $\mathrm{p}$ & $<0.001$ & $<0.05$ & 0.77 & $<0.001$ & 0.77 & 0.91 & 0.15 \\
\hline \multicolumn{8}{|c|}{ Child race/ethnicity } \\
\hline Hispanic & $47(31)$ & $75(49)$ & $38(25)$ & $21(14)$ & $83(52)$ & $77(48)$ & $38(25)$ \\
\hline $\begin{array}{l}\text { Non- } \\
\text { Hispanic } \\
\text { Black }\end{array}$ & $90(35)$ & $140(54)$ & $41(16)$ & $39(15)$ & $161(60)$ & $149(55)$ & $73(27)$ \\
\hline $\begin{array}{l}\text { Non- } \\
\text { Hispanic } \\
\text { White }\end{array}$ & $268(31)$ & $471(55)$ & $248(29)$ & $70(8)$ & $691(80)$ & $693(81)$ & $\begin{array}{l}240 \\
(28)\end{array}$ \\
\hline $\begin{array}{l}\text { Non- } \\
\text { Hispanic } \\
\text { Other }\end{array}$ & $58(31)$ & $106(57)$ & $48(26)$ & $24(13)$ & $138(74)$ & $136(73)$ & $65(35)$ \\
\hline $\mathrm{p}$ & $<0.05$ & 0.38 & $<0.01$ & $<0.001$ & $<0.001$ & $<0.001$ & 0.28 \\
\hline \multicolumn{8}{|c|}{ Child insurance } \\
\hline Public & $179(39)$ & $244(53)$ & $80(17)$ & $68(15)$ & $263(56)$ & $254(54)$ & $\begin{array}{l}106 \\
(23)\end{array}$ \\
\hline Private & $273(29)$ & $526(55)$ & $286(30)$ & $79(8)$ & $781(81)$ & $769(80)$ & $\begin{array}{l}294 \\
(31)\end{array}$ \\
\hline Self-Pay & $11(26)$ & $22(51)$ & $9(21)$ & $7(16)$ & $29(67)$ & $32(74)$ & $16(37)$ \\
\hline $\mathrm{p}$ & $<0.001$ & 0.24 & $<0.001$ & $<0.001$ & $<0.001$ & $<0.001$ & $<0.001$ \\
\hline \multicolumn{8}{|c|}{ Child Opportunity Index } \\
\hline Very low & $64(34)$ & $100(54)$ & $35(19)$ & $30(16)$ & $113(58)$ & $103(53)$ & $50(26)$ \\
\hline Low & $80(29)$ & $132(48)$ & $54(19)$ & $37(13)$ & $192(68)$ & $187(66)$ & $65(23)$ \\
\hline Moderate & $81(36)$ & $124(54)$ & $50(22)$ & $23(10)$ & $154(67)$ & $152(66)$ & $58(25)$ \\
\hline High & $85(33)$ & $144(56)$ & $75(29)$ & $32(13)$ & $196(75)$ & $190(73)$ & $76(29)$ \\
\hline Very high & $153(30)$ & $292(58)$ & $161(32)$ & $32(6)$ & $418(82)$ & $423(83)$ & $\begin{array}{l}167 \\
(33)\end{array}$ \\
\hline $\mathrm{p}$ & 0.32 & 0.26 & $<0.001$ & $<0.001$ & $<0.001$ & $<0.001$ & 0.13 \\
\hline
\end{tabular}


Doi: $10.32481 /$ djph.2021.12.015

\begin{tabular}{|l|l|l|l|l|l|l|l|}
\hline $\begin{array}{l}\text { Non-Rural } \\
(\text { RUCA }< \\
4)\end{array}$ & $412(32)$ & $710(55)$ & $343(27)$ & $134(11)$ & $949(73)$ & $934(72)$ & $\begin{array}{l}379 \\
(29)\end{array}$ \\
\hline $\begin{array}{l}\text { Rural } \\
(\text { RUCA } \geq \\
4)\end{array}$ & $51(30)$ & $82(48)$ & $32(19)$ & $20(12)$ & $124(71)$ & $121(69)$ & $37(21)$ \\
\hline$p$ & 0.56 & $<0.05$ & 0.06 & 0.10 & 0.43 & 0.19 & $<0.05$ \\
\hline
\end{tabular}

\section{Discussion}

This is the first study that comprehensively evaluates disparities in caregiver attitudes and beliefs about the COVID-19 vaccine for their children in Delaware. This is also the first study to evaluate these disparities leveraging EHR and geocoded data to assess individual and neighborhood level sociodemographics and evaluating constructs from the HBM. Fifty-four percent of caregivers in this representative sample intended to vaccinate their children against COVID-19, lower than what was described by Kelly and colleagues at the start of the pandemic and higher than what was reported in a recent Kaiser Family Foundation poll. ${ }^{6,18}$ Importantly, $46 \%$ of caregivers were unsure or would not vaccinate their children against COVID-19, with caregivers of younger children and from communities of color, rural communities, and disadvantaged communities being more hesitant. It is among these groups that public health strategies to improve COVID-19 vaccine uptake will be critical. This study is also the first to explore which caregiver health beliefs and cues to action are related to intention to vaccinate children in these subgroups, which is important when tailoring communication strategies to increase pediatric COVID-19 vaccine uptake in these communities.

There were significant differences in intention to vaccinate by child sociodemographics, with caregivers of children under 16 years, of Black race, with public insurance, from rural neighborhoods, and from neighborhoods with lower COI being less likely to intend to vaccinate their children against COVID-19. These findings support the racial and socioeconomic disparities in COVID-19 vaccine hesitancy found in adult studies and the few pediatric studies among caregivers of children in the United States. ${ }^{15,25-28}$ This study adds to prior studies by using EHR and geocoded variables to better understand the impact of a child's neighborhood on intention to vaccinate, including highlighting the impact of social determinants of health and rurality on intent to vaccinate and health beliefs. While these sociodemographic variables often have complex relationships with one another, this study also highlights the need to recognize each as important and independent contributors to beliefs about COVID-19 vaccination. Similar to recent studies, ${ }^{20}$ age was an important factor influencing caregiver intention to vaccinate their children against COVID-19. At the time of the survey, the vaccine was available to youth 16 years of age and older, and caregivers of children 16 years of age and older were more likely than caregivers of younger children to intend to vaccinate their children. This finding provides hope that as the COVID-19 vaccines become available to younger children, including now being available to children 12 years of age and older, caregivers may become more confident about vaccination for their children.

Similar to HBM studies evaluating caregiver beliefs about the seasonal and H1N1 influenza vaccine and to those evaluating adult beliefs about the COVID-19 vaccine for themselves, ${ }^{23-30}$ this study highlights the concerns about vaccine safety and efficacy that caregivers of all backgrounds have when considering whether to vaccinate their children. This study also 
demonstrates that fewer caregivers of younger children, compared to caregivers of older children, believed that their children are susceptible to COVID-19 and would have severe disease from COVID-19, which are messages emphasized by early epidemiological studies and amplified by the media. Fewer caregivers from rural neighborhoods also believed that their child would have severe disease from COVID-19. These findings point to modifiable beliefs that should be targeted with more focused messaging, both emphasizing the efficacy and safety of the COVID-19 vaccine in a way that is relatable and relevant to families but also stressing the transmissibility and burden of COVID-19 among younger children and the importance of herd immunity to public health. Not surprisingly, the overwhelming majority of caregivers in this study would be influenced by messaging from health experts and doctors, so it is important to leverage these communicators for general public health messaging. However, fewer caregivers from communities of color and disadvantaged communities were influenced by health experts and doctors, a finding likely driven by structural racism, mistrust of the medical system, systematic inequities, and a history of discrimination in research that have led to distrust in the healthcare system. ${ }^{14,35}$ Therefore it is critically important to develop a deeper understanding of how to reach these communities, including ways to improve access and trust and reduce structural racism within the healthcare system, such as identifying trusted champions within these communities and developing a more diverse healthcare workforce.

There were some limitations to this study. While $60 \%$ of eligible families who received the vaccine survey completed it, if we take into account the number of eligible families who received an invitation to participate in the original study the overall participation rate was $10 \%$. While this is not unexpected for a large-scale electronic survey study, it may lend itself to sampling bias. However, by oversampling for certain subgroups this study was able to achieve a sample otherwise very representative of the population. Notably, this study was conducted in four states in the Delaware Valley region of the United States. While the population was diverse, it is possible that there are geographic and political differences that are not accounted for in this study. Another limitation is that youth health beliefs were not assessed. Caregivers of older youth may include their child in deciding whether or not to receive the COVID-19 vaccine; therefore, future studies should also evaluate youth and adolescent beliefs. Finally, this study utilized EHR data like race/ethnicity and geocoded data to evaluate social determinants of health. While it is possible that self-reported data may have provided a more accurate picture of a family's sociodemographics, the fact that the disparities found in this study were consistent with other studies and that neighborhood indicators of social determinants of health like RUCA codes and COI performed as well as individual indicators like insurance status validates the use of the EHR in this study and underscores the importance of evaluating community-level factors. It also highlights the potential to use linked EHR data to evaluate the associations between health factors like prior child vaccination history and disease risk factors like obesity with caregiver beliefs about the COVID-19 vaccine for their children.

\section{Conclusion}

This study describes the sociodemographic disparities in Delaware caregiver intention to vaccinate their children against COVID-19 and beliefs influencing this decision at a critical time when vaccines are more available to children, leveraging both caregiver-reported and EHR data. This study highlights the need to tailor COVID-19 vaccine public health messaging and strategies in Delaware for communities of color, rural communities, disadvantaged communities, and caregivers of young children in order to promote equitable pediatric vaccine uptake. 
Doi: $10.32481 /$ djph.2021.12.015

\section{Acknowledgements}

We would like to thank Dr. Kara Odom Walker, MD, MPH, MSHS for her review of this manuscript and the team at the Nemours Center for Healthcare Delivery Science for their input on the parent study, The Impact of COVID-19 on Families and Pediatric Healthcare Delivery. This work was supported by the ACCEL/Delaware Clinical and Translational Research Program (grant number NIGMS U54 GM104941) [to TP and PE]. The National Institute of General Medical Sciences had no role in the design and conduct of the study.

Dr. Phan can be contacted at tphan@nemours.org

\section{References}

1. Ahmad, F. B., Cisewski, J. A., Miniño, A., \& Anderson, R. N. (2021, April 9). Provisional mortality data - United States, 2020. MMWR. Morbidity and Mortality Weekly Report, 70(14), 519-522. PubMed https://doi.org/10.15585/mmwr.mm7014e1

2. Moore, J. T., Ricaldi, J. N., Rose, C. E., Fuld, J., Parise, M., Kang, G. J., . . .. Honein, M. A., $\&$ the COVID-19 State, Tribal, Local, and Territorial Response Team. (2020, August 21). Disparities in incidence of COVID-19 among underrepresented racial/ethnic groups in counties identified as hotspots during June 5-18, 2020-22 states, February-June 2020. MMWR. Morbidity and Mortality Weekly Report, 69(33), 1122-1126. Retrieved from https://www.cdc.gov/mmwr/volumes/69/wr/mm6933e1.htm PubMed

3. Alcendor, D. J. (2020, July 30). Racial disparities-associated COVID-19 mortality among minority populations in the US. Journal of Clinical Medicine, 9(8), 2442. PubMed https://doi.org/10.3390/jcm9082442

4. Ndugga, N., Hill, L., Artiga, S., \& Haldar, S. (2021). Latest Data on COVID-19

Vaccinations Race/Ethnicity. Kaiser Family Foundation. https://www.kff.org/coronaviruscovid-19/issue-brief/latest-data-on-covid-19-vaccinations-race-ethnicity/

5. Centers for Disease Control. (2021). COVID-19 vaccinations in the United States. COVID data tracker. https://covid.cdc.gov/covid-data-tracker/\#vaccinations

6. Hamel, L., Lopes, L., Sparks, G., Stokes, M., \& Brodie, M. (2021). KFF COVID-19 Vaccine Monitor - April 2021. https:/www.kff.org/coronavirus-covid-19/poll-finding/kffcovid-19-vaccine-monitor-april-2021/

7. Press, V. G., Huisingh-Scheetz, M., \& Arora, V. M. (2021). Inequities in technology contribute to disparities in COVID-19 vaccine distribution. JAMA Health Forum, 2(3), e210264. Retrieved from https://jamanetwork.com/journals/jama-healthforum/fullarticle/2777888 https://doi.org/10.1001/jamahealthforum.2021.0264

8. Zimet, G. D., Silverman, R. D., \& Fortenberry, J. D. (2021, April). Coronavirus disease 2019 and vaccination of children and adolescents: Prospects and challenges. The Journal of Pediatrics, 231, 254-258. PubMed https://doi.org/10.1016/j.jpeds.2020.11.002

9. Guay, M., Gosselin, V., Petit, G., Baron, G., \& Gagneur, A. (2019). Determinants of vaccine hesitancy in Quebec: A large population-based survey. Human Vaccines \&

Immunotherapeutics, 15(11), 2527-2533. PubMed https://doi.org/10.1080/21645515.2019.1603563 
10. Schellenberg, N., \& Crizzle, A. M. (2020, August). Vaccine hesitancy among parents of preschoolers in Canada: A systematic literature review. Can J Public Health, 111(4), 562584. PubMed https://doi.org/10.17269/s41997-020-00390-7

11. Quinn, S., Jamison, A., Musa, D., Hilyard, K., \& Freimuth, V. (2016, December 29). Exploring the continuum of vaccine hesitancy between African American and White adults: Results of a qualitative study. PLoS Currents, 8 , ecurrents.outbreaks.3e4a5ea39d8620494e2a2c874a3c4201. PubMed

12. Fisher, K. A., Bloomstone, S. J., Walder, J., Crawford, S., Fouayzi, H., \& Mazor, K. M. (2020, December 15). Attitudes toward a potential SARS-CoV-2 vaccine: A survey of US adults. Annals of Internal Medicine, 173(12), 964-973. PubMed https://doi.org/10.7326/M20-3569

13. Callaghan, T., Moghtaderi, A., Lueck, J. A., Hotez, P., Strych, U., Dor, A., . . Motta, M. (2021, March). Correlates and disparities of intention to vaccinate against COVID-19. Soc Sci Med, 272, 113638. PubMed https://doi.org/10.1016/j.socscimed.2020.113638

14. Zhang, Y., \& Fisk, R. J. (2021, March). Barriers to vaccination for coronavirus disease 2019 (COVID-19) control: Experience from the United States. Glob Health J, 5(1), 51-55. PubMed

15. Romer, D., \& Jamieson, K. H. (2020, October). Conspiracy theories as barriers to controlling the spread of COVID-19 in the U.S. Soc Sci Med, 263, 113356. PubMed https://doi.org/10.1016/j.socscimed.2020.113356

16. Montalti, M., Rallo, F., Guaraldi, F., Bartoli, L., Po, G., Stillo, M., .. . Gori, D. (2021, April 10). Would parents get their children vaccinated against SARS-CoV-2? Rate and predictors of vaccine hesitancy according to a survey over 5000 families from Bologna, Italy. Vaccines, 9(4), 366. PubMed https://doi.org/10.3390/vaccines9040366

17. Yılmaz, M., \& Sahin, M. K. (2021, September). Parents' willingness and attitudes concerning the COVID-19 vaccine: A cross-sectional study. International Journal of Clinical Practice, 75(9), e14364. PubMed https://doi.org/10.1111/ijcp.14364

18. Kelly, B. J., Southwell, B. G., McCormack, L. A., Bann, C. M., MacDonald, P. D. M., Frasier, A. M., ... Squiers, L. B. (2021, April 12). Predictors of willingness to get a COVID-19 vaccine in the U.S. BMC Infectious Diseases, 21(1), 338. PubMed https://doi.org/10.1186/s12879-021-06023-9

19. Bell, S., Clarke, R., Mounier-Jack, S., Walker, J. L., \& Paterson, P. (2020, November 17). Parents' and guardians' views on the acceptability of a future COVID-19 vaccine: A multimethods study in England. Vaccine, 38(49), 7789-7798. PubMed https://doi.org/10.1016/j.vaccine.2020.10.027

20. Szilagyi, P. G., Shah, M. D., Delgado, J. R., Thomas, K., Vizueta, N., Cui, Y., . . Kapteyn, A. (2021, October). Parents' intentions and perceptions about COVID-19 vaccination for their children: Results from a national survey. Pediatrics, 148(4), e2021052335. PubMed https://doi.org/10.1542/peds.2021-052335

21. Pfizer. (2021). Pfizer-BioNTech announce positive topline results of pivotal COVID-19 vaccine study in adolescents. https://www.pfizer.com/news/press-release/press-releasedetail/pfizer-biontech-announce-positive-topline-results-pivotal 
22. Moderna. (2021). Moderna announces first participants dosed in phase $2 / 3$ study of COVID19 vaccine candidate in pediatric population. https://investors.modernatx.com/newsreleases/news-release-details/moderna-announces-first-participants-dosed-phase-23-study-0

23. Akis, S., Velipasaoglu, S., Camurdan, A. D., Beyazova, U., \& Sahn, F. (2011, September). Factors associated with parental acceptance and refusal of pandemic influenza A/H1N1 vaccine in Turkey. European Journal of Pediatrics, 170(9), 1165-1172. PubMed https://doi.org/10.1007/s00431-011-1425-6

24. Chen, M. F., Wang, R. H., Schneider, J. K., Tsai, C. T., Jiang, D. D. S., Hung, M. N., \& Lin, L. J. (2011, January). Using the Health Belief Model to understand caregiver factors influencing childhood influenza vaccinations. Journal of Community Health Nursing, 28(1), 29-40. PubMed https://doi.org/10.1080/07370016.2011.539087

25. Teitler-Regev, S., Shahrabani, S., \& Benzion, U. (2011). Factors affecting intention among students to be vaccinated against A/H1N1 influenza: A Health Belief Model Approach. Advances in Preventive Medicine, 2011, 353207. PubMed

26. Wong, L. P., Alias, H., Wong, P. F., Lee, H. Y., \& AbuBakar, S. (2020, September 1). The use of the health belief model to assess predictors of intent to receive the COVID-19 vaccine and willingness to pay. Human Vaccines \& Immunotherapeutics, 16(9), 2204-2214. $\underline{\text { PubMed https://doi.org/10.1080/21645515.2020.1790279 }}$

27. Mercadante, A. R., \& Law, A. V. (2021, September). Will they, or Won't they? Examining patients' vaccine intention for flu and COVID-19 using the Health Belief Model. Res Social Adm Pharm, 17(9), 1596-1605. PubMed https://doi.org/10.1016/j.sapharm.2020.12.012

28. Chu, H., \& Liu, S. (2021, August). Integrating health behavior theories to predict American's intention to receive a COVID-19 vaccine. Patient Education and Counseling, 104(8), 1878-1886. PubMed https://doi.org/10.1016/j.pec.2021.02.031

29. Shmueli, L. (2021, April 26). Predicting intention to receive COVID-19 vaccine among the general population using the health belief model and the theory of planned behavior model. BMC Public Health, 21(1), 804. PubMed https://doi.org/10.1186/s12889-021-10816-7

30. Coe, A. B., Elliott, M. H., Gatewood, S. B. S., Goode, J. V. R., \& Moczygemba, L. R. (2021). Perceptions and predictors of intention to receive the COVID-19 vaccine. Res Social Adm Pharm, S1551-7411(21), 00164-00169. doi:

31. Agriculture, U. S. D. A. (2020). Rural-Urban Commuting Area Codes. https://www.ers.usda.gov/data-products/rural-urban-commuting-area-codes/

32. Harris, P. A., Taylor, R., Thielke, R., Payne, J., Gonzalez, N., \& Conde, J. G. (2009, April). Research electronic data capture (REDCap) - A metadata-driven methodology and workflow process for providing translational research informatics support. Journal of Biomedical Informatics, 42(2), 377-381. PubMed https://doi.org/10.1016/j.jbi.2008.08.010

33. Fan, W., \& Yan, Z. (2010). Factors affecting response rates of the web survey: A systematic review. Computers in Human Behavior, 26(2), 132-139. https://doi.org/10.1016/j.chb.2009.10.015

34. Kids, D. D. (2021). Child Opportunity Index (COI) 2021. https://www.diversitydatakids.org/child-opportunity-index 
35. Feagin, J., \& Bennefield, Z. (2014, February). Systemic racism and U.S. health care. Soc Sci Med, 103, 7-14. PubMed https://doi.org/10.1016/j.socscimed.2013.09.006

Copyright (c) 2021 Delaware Academy of Medicine / Delaware Public Health Association.

This is an Open Access article distributed under the terms of the Creative Commons Attribution Non-Commercial License (https://creativecommons.org/licenses/by-nc-nd/4.0/) which permits unrestricted non-commercial use, distribution, and reproduction in any medium, provided the original work is properly cited. 